\title{
Cortar ou investir? Ações estratégicas para enfrentar a crise provocada pela Covid-19
}

\author{
Rosiele Fernandes Pinto \\ (iD) Ivano Ribeiro \\ Cláudia Brito Cirani \\ (D) José Eduardo Storopoli \\ iD Heidy Rodriguez Ramos
}

Cite as

American Psychological Association (APA)

Pinto, R. F., Ribeiro, I., Cirani, C. B., Storopoli, J. E., \& Ramos, H. R. (2020, July/Sept.). Cortar ou investir? Ações estratégicas para enfrentar a crise provocada pela Covid-19. Editorial. Iberoamerican Journal of Strategic Management (IJSM), 19(3), 1-5.

https://doi.org/10.5585/riae.v19i3.18391.

$(A B N T-N B R$ 6023:2018)

PINTO, R. F.; RIBEIRO, I.; CIRANI, C. B.; STOROPOLI, J. E.; RAMOS, H. R. Cortar ou investir? Ações estratégicas para enfrentar a crise provocada pela Covid-19. Iberoamerican Journal of Strategic Management (IJSM). v. 19, n. 3, p. 1-5, July/Sept. 2020. Editorial. Disponível em: https://doi.org/10.5585/riae.v19i3.18391.

A Revista Ibero-Americana de Estratégia tem se mostrado em sintonia com a atual crise provocada pela COVID-19 e os impactos causados tanto na pesquisa como nas organizações. No editorial da edição anterior sugerimos temas de pesquisa bem como as diretrizes éticas que os pesquisadores devem adotar ao pesquisar os efeitos da pandemia. Nesse editorial, nosso foco está em entender como historicamente as empresas responderam a períodos de crise e de que forma essas experiências podem direcionar as empresas para o enfrentamento da crise COVID19.

Pouca pesquisa tem sido realizada sobre estratégias que podem ajudar as empresas a sobreviverem a uma recessão, progredirem durante uma recuperação de crescimento lento e estarem prontas para vencer quando os bons tempos retornarem (Gulati, Nohria, \& Wohlgezogen, 2010). Isso nos remete à necessidade de compreendermos quais ações as empresas podem empreender para responder efetivamente aos períodos de crise, visto que os estudos no campo da estratégia estão mais focados aos períodos de crescimento. 


\section{CRISE PROVOCADA PELA COVID-19 E O IMPACTO NAS EMPRESAS}

Ao longo da história, as economias têm experienciado crises de várias naturezas, essas crises têm em comum o potencial devastador individual, social, econômico e natural, como o colapso de empresas e indústrias, perdas massivas de empregos, precariedade e danos naturais (Wenzel, Stanske, \& Lieberman, 2020). A crise provocada pela COVID-19 exigiu dos governos medidas severas de isolamento social, que consequentemente ameaçaram a sobrevivência das empresas em todo o mundo. Dentre os diversos setores afetados, destacam-se: o setor aéreo, varejo, turismo, esportes e eventos (Krishnamurthy, 2020).

No Brasil, dados do Instituto Brasileiro de Geografia e Estatística (IBGE, 2020) sobre o impacto da Covid-19 apontam que em 2020, até a segunda quinzena do mês de agosto, 47,6\% das empresas haviam tido dificuldades de acesso aos fornecedores de insumos e matéria-prima, prejudicando consideravelmente suas atividades. Sobre a capacidade de honrar os compromissos, $44,9 \%$ passaram por problemas financeiros para pagamentos relativos aos tributos, fornecedores, salários, aluguéis e energia elétrica. Apesar da crise provocar, em algumas situações, certa inércia organizacional, os dados do IBGE apontam que mesmo com as adversidades provocadas pela pandemia, 30,6\% das empresas adotaram algum tipo de medida, como: passou a comercializar novos produtos ou serviços; alterou o método de entrega, com a entrada no e-commerce; adiou o pagamento de impostos; conseguiu linha de crédito emergencial para pagamento da folha salarial; adotou trabalho domiciliar; antecipou férias dos funcionários; realizou campanhas de informação e prevenção; e adotou medidas de higiene. Isso mostra que as empresas realizaram algum tipo de movimento para reagir à crise, porém eles se caracterizam mais como ações emergenciais, sinalizando a necessidade da adoção de ações estratégicas mais planejadas e efetivas.

\section{COMO AS EMPRESAS EXPERIENCIAM AS CRISES?}

Encontrar a estratégia adequada para as empresas é sempre desafiador e quando se trata de um período de turbulência esse desafio toma proporções mais complexas. Durante uma recessão, as empresas enfrentam um dilema entre investir para aproveitar as oportunidades emergentes ou reter os recursos financeiros para se proteger contra a crise (Nason \& Patel, 2016). Há uma forte tendência de as empresas recorrerem a ações de retrenchment, que se refere a ações de recuperação de curto prazo orientadas para a eficiência, como downsizing, redução de custos, venda de ativos e desinvestimento de negócios. No entanto, alguns estudos têm mostrado uma ação inversa a essa, sendo investir uma alternativa para lidar com a crise. 
Mann e Byun (2017) analisaram as estratégias de retrenchment e investimento dos varejistas nos EUA em resposta à Grande Recessão nos anos compreendidos entre 2008 a 2011 e encontraram mais relatos de investimento do que retrenchment. Nesse estudo foram observados: fechamentos de lojas e falências como estratégias de retrenchment; e a expansão de mercado, desenvolvimento de produtos, desenvolvimento de serviços, aquisições, parcerias estratégicas e responsabilidade social corporativa como estratégias de investimento. $\mathrm{O}$ estudo constatou que os varejistas que conseguiram equilibrar os esforços de retrenchment com as oportunidades de investimento estavam melhor posicionados para enfrentar a recessão, incluindo exemplos de sucesso de empresas como Starbucks, Macy's e Walmart. Por exemplo, a Starbucks explorou os recursos existentes leiloando ativos não essenciais, fechou lojas e, simultaneamente, investiu em energia renovável e explorou novas oportunidades de investimento, abrindo quase 1000 lojas no exterior.

A recessão também pode ser um bom momento para empreendedores desenvolverem novas formas de fazer as coisas, estimulando a adoção de novas tecnologias, segundo defende o estudo sobre a crise financeira global de Hausman e Johnston (2014). De acordo com esse estudo, a história apoia a noção de que o aumento da pressão econômica geralmente alimenta soluções criativas que estimulam o crescimento econômico, por exemplo, a grande depressão da década de 1930 foi uma das épocas mais produtivas do século XX. Durante esse tempo, as pessoas adotaram muitas das tecnologias desenvolvidas na década de 1920 para alcançar melhor produtividade.

\section{POSSÍvEIS AÇÕES PARA O ENFRENTAMENTO DA CRISE}

Vimos que as empresas que combinaram redução de custos e investimento promoveram uma melhor resposta à crise. Gulati, Nohria e Wohlgezogen (2010) defendem que as empresas que dominam o equilíbrio entre cortar custos para sobreviver hoje e investir para crescer amanhã, a partir de uma combinação de movimentos defensivos e ofensivos, têm ganhos após uma recessão. Esses autores classificaram as abordagens de gerenciamento das empresas durante a recessão em quatro tipos: empresas com foco na prevenção, as quais fazem movimentos principalmente defensivos e estão mais preocupadas do que seus concorrentes em evitar perdas e minimizar os riscos de declínio; empresas com foco em promoção, as quais investem em movimentos ofensivos; empresas pragmáticas, as quais combinam movimentos defensivos e ofensivos; e por último empresas progressistas, as quais atingem uma combinação ideal de defesa e ataque. Portanto, a adequação entre os cortes necessários para a manutenção 
das operações e os investimentos para o aproveitamento das novas oportunidades de negócio podem ser a saída para o enfrentamento do período de crise.

Em uma edição especial, publicada no Strategic Management Journal, Wenzel, Stanske e Lieberman (2020) discutiram artigos que fornecem insights sobre as possíveis respostas estratégicas das empresas à crise, tendo identificado quatro tipos de respostas: 1- Saída, em algumas situações a empresa pode encerrar suas atividades como resposta à crise, o fechamento da empresa pode ser nesse caso uma solução; 2-Retrenchment, apesar de ser apontada como uma estratégia bastante utilizada, os autores chamam atenção para a necessidade de respostas alternativas a essa, visto que o retrenchment pode causar a erosão dos recursos, especialmente quando uma crise dura por um longo período de tempo. Sua adoção sem um planejamento pode provocar mudanças bruscas e inapropriadas para o negócio; 3- Perseverar, essa ação pode apresentar uma aparente zona de conforto diante da crise e contribuir para sustentar a sobrevivência da empresa no médio prazo. No entanto, será difícil, senão impossível, implementar respostas satisfatórias se uma crise durar muito tempo; 4- Inovação, a realização da renovação estratégica pode ser uma resposta efetiva à crise.

De fato, a inovação tem se apresentado como uma possível alternativa para as empresas enfrentarem a natureza complexa da crise desencadeada pela COVID-19. Nações em todo o mundo se voltaram para iniciativas sociais que refletem os princípios de inovação social. Com seu caráter colaborativo, a inovação social pode ajudar a construir um futuro mais participativo e inclusivo. Ações neste sentido podem auxiliar tanto para a melhoria do desempenho econômico como no atendimento de demandas da sociedade (Pol \& Ville, 2009).

Além das ações apontadas, as empresas devem considerar o cuidado com a saúde, a qual se tornou parte integrante das atividades e o home office que tem se apresentado como uma opção para a redução de custos (Krishnamurthy, 2020). É importante destacar que a implementação de toda e qualquer resposta à crise vai depender da agilidade com que as empresas irão responder. O desenvolvimento de práticas, técnicas e métodos de trabalho que permitam respostas rápidas devem ser ações consideradas no direcionamento dos negócios, assim como a adoção de mecanismos que facilitem a adaptabilidade organizacional às complexas demandas sociais, interesses divergentes e cenários incertos (Janssen \& van der Voort, 2020).

A crise é uma adversidade ambiental, porém ela pode ser propulsora para novos negócios, processos, produtos ou serviços. Para isso, as empresas demandam direcionamento estratégico, onde o conselho, a governança e os gestores exercem papel central. Enquanto as equipes gerenciais se concentram em tomar decisões rápidas para proteger os funcionários, 
atender as necessidades dos clientes e se comunicar com os stakeholders, os conselhos precisam equilibrar decisões de resposta à crise, com o pensamento além dos desafios imediatos (Hirt, Huber, Lund, \& Spielmann, 2020). Esperamos que esse editorial, além de ter apontado possíveis ações que empresas podem adotar no enfrentamento da crise provocada pela COVID-19, também possa inspirar estudos futuros sobre o papel do conselho e dos gestores. Ampliar o debate sobre esses temas contribui para um melhor direcionamento às empresas.

\section{Referências}

Gulati, R., Nohria, N., \& Wohlgezogen, F. (2010). Roaring out of recession. Harvard Business Review, 88(3), 62-69.

Hausman, A., \& Johnston, W. J. (2014). The role of innovation in driving the economy: Lessons from the global financial crisis. Journal of Business Research, 67(1), 2720-2726.

Hirt, M., Huber, C., Lund, F., \& Spielmann, N. (2020). Boards in the time of coronavirus. McKinsey \& Company. Recuperado em 15 de setembro, 2020, de https://www.mckinsey.com/ /media/McKinsey/Business\%20Functions/Strategy\%20and\%2 0Corporate $\% 20$ Finance/Our\%20Insights/Boards\%20in\%20the $\% 20$ time $\% 20$ of $\% 20$ coronavi rus/Boards-in-the-time-of-coronavirus.pdf.

Instituto Brasileiro de Geografia e Estatística - IBGE. (2020). Pesquisa pulso empresa: Impacto da Covid-19 nas empresas. Rio de Janeiro: IBGE, Recuperado em 20 de setembro, 2020, de https://www.ibge.gov.br/estatisticas/sociais/saude/28291-pesquisa-pulso-empresaimpacto-da-covid-19-nas-empresas.html.

Janssen, M., \& van der Voort, H. (2020). Agile and adaptive governance in crisis response: Lessons from the COVID- 19 pandemic. International Journal of Information Management, in press. https://doi.org/10.1016/j.ijinfomgt.2020.102180.

Krishnamurthy, S. (2020). The future of business education: A commentary in the shadow of the Covid-19 pandemic. Journal of Business Research, 117, 1-5.

Mann, M., \& Byun, S. (2017). To retrench or invest? Turnaround strategies during a recessionary time. Journal of Business Research, 80, 24-34.

Nason, R. S., \& Patel, P. C. (2016). Is cash king? Market performance and cash during a recession. Journal of Business Research, 69(10), 4242-4248.

Pol, E., \& Ville, S. (2009). Social innovation: Buzz word or enduring term? Journal of SocioEconomics, 38(6), 878-885.

Wenzel, M., Stanske, S., \& Lieberman, M. (2020). Strategic responses to crisis. Strategic Management Journal, 41(Special Issue), 7-18. 